\title{
Trends of the German biotech market
}

\author{
Marina Reshetnikova ${ }^{1, *}$, Irina Pugacheva ${ }^{1}$, and Yulia Lukina ${ }^{1}$ \\ ${ }^{1}$ RUDN University, 117198 Moscow, Russian Federation
}

\begin{abstract}
Over the past few years, biotechnology has become one of the most promising sectors of the economy. The biotech industry has been a vital instrument in developing and supplying COVID-19 vaccines in record time. The article discusses global trends in technology development in this area. The major players in the global biotechnology market have been identified, and the positions of Germany have been determined. The authors defined a crucial role of the biotech sector in German innovation and discuss the main trends in the growth of the German biotechnology market with a volume forecast of biotechnology output in Germany for 2020-2023.
\end{abstract}

\section{Introduction}

Over the past few years, biotechnology has become one of the most promising sectors of the economy. However, it combines growth potential and high risk, so companies in this industry depend on investors greatly.

Today all biotechnologies are divided into two large groups: classical and modern [1]. The first group is based on classical methods such as crossing and fermentation to produce and modify existing products using living microorganisms. The group of modern biotechnologies relies on genetic engineering methods, such as manipulating genes, cells, and tissues and altering DNA.

It is customary to separate biotechnologies using a color system: red - medicine, white industry, green - agriculture, blue - development using marine organisms, gray environmental protection [2].

The global biotechnology market is estimated at $\$ 752.88$ billion in 2020 and is expected to grow at a CAGR of $15.83 \%$ from 2021 to 2028 [3]. The growth is mainly due to restructuring by companies of their operations and recovery from COVID-19, which previously led to restrictive containment measures, including social distancing, distant working, and the closure of commercial activities, which led to operational problems. Also, the market's growth might be explained by favorable government initiatives aimed at developing the biotechnological sector worldwide. In addition, government initiatives are focused on modernizing the drug regulatory system, standardizing clinical trials, improving cost recovery policies, and accelerating the product approval process, which provides the market with opportunities for rapid growth.

The German biotech market is one of the largest not only in Europe but worldwide. The volume of biotechnology products is growing every year in correlation with the level of innovation in the country.

\footnotetext{
* Corresponding author: reshetnikova-ms@rudn.ru
} 
For the most outstanding development of innovation in Germany, there is a very close relationship between German politics, business, and science. In 2016, Germany became the leader in R\&D investment as the federal government and German industry spent 92.2 billion euros on investments in R\&D (2.94\% of the country's GDP) [4].

\section{Materials and methods}

The main methods used in this study were the systemic and dialectical approaches to studying changes in economic trends in the development of biotechnology in Germany.

For the analysis of quantitative indicators, the authors used a combination of comparison and classification methods, media scanning, and crowdsourcing. The information base was based on annual reference books published by official institutions in Germany, statistical data from international publications devoted to biotechnology, articles, and monographs of European economists. The main scientific provisions of this work were developed by the authors independently. The forecast of the German biotech market size was made using the econometric model of multiple linear regression.

\section{Results}

\subsection{Major players in the biotechnology market}

Most of the biotech products are created in the United States. As a result, this country is the largest biotechnology market in the world (48\% in 2019). Also, the leading position is indicated by the number of patents registered in the biotechnology sector. In 2019, the United States showed the highest value - 5812 patents, which is about $42 \%$ of the total number in the world's countries [5].

The second position after the United States in terms of the biotechnological market size is occupied by the Asia-Pacific region, where China, Japan, and South Korea dynamically develop biotechnologies. It is these countries that demonstrate high patenting activity, occupying the next position after the leader. In 2019, 1,575 were registered in Japan, 1,539 in China, and 973 biotechnology patents in South Korea. Analysts estimate the Asia-Pacific region is expected to expand with the fastest growth at $16.8 \%$ from 2021 to 2028 . According to experts, the Chinese market will demonstrate a significant change in the coming years more than $10 \%$. Population growth, coupled with the growing demand for bio-agricultural products, is also one of the main factors driving the development of the market in this region [6].

Europe closes the top three, occupying $18 \%$ of the global biotechnology market. The most remarkable development of biotechnology the authors observed in Germany, Great Britain, and France. The UK has some of the highest funding volumes in Europe, and Germany has some of the most increased venture capital investments. It is worth noting that the most significant number of research institutions and specialized educational entities in biotechnology is concentrated in Germany. For this reason, the country is the regional leader in terms of registered patents - 636 pcs. for 2019, followed by France with 515 patents and the UK with 485 patents [7].

The global biotechnology industry is focused on red biotechnology due to the emergence and spread of new diseases that do not lend themselves to traditional treatment - the extreme stages of cancer, congenital genetic pathologies, autoimmune diseases.

The main trends in recent years are:

- targeted delivery of drugs in the human body using nanoparticles for the treatment of cancer and cardiovascular diseases;

- the use of biocompatible materials for the possibility of replacing tissues and organs in the body. 
The creation of new biopharmaceuticals requires additional clinical trials, and the result is superior to conventional chemically synthesized drugs.

In addition, the COVID-19 pandemic acts as a positive catalyst for market growth as it spurs increased participation by the biotech industry with diagnostic companies, drug manufacturers, research laboratories, and multinational pharmaceutical companies to develop therapeutic molecules to combat the virus. For example, in March 2020, Pfizer Inc. collaborated with BioNTech SE to create a vaccine for COVID-19 BNT162. In addition, BioNTech SE has developed a vaccine using mRNA technology against COVID-19 [8].

For several years, the main trends in "green" biotechnology in agriculture have been developing markets for biopesticides and genetically modified organisms to create more hardy plant crops and increase agricultural production.

In industry, the primary trend is the creation of biofuels. The market is growing thanks to a transparent government policy on using fuels from renewable raw materials. This type of fuel will help reduce the consumption of traditional energy sources and improve the environmental situation.

\subsection{Biotech market in Germany}

The biotechnology market in Germany is one of the largest in Europe; in terms of the number of companies, the country is second only to France and Spain (Fig. 1).

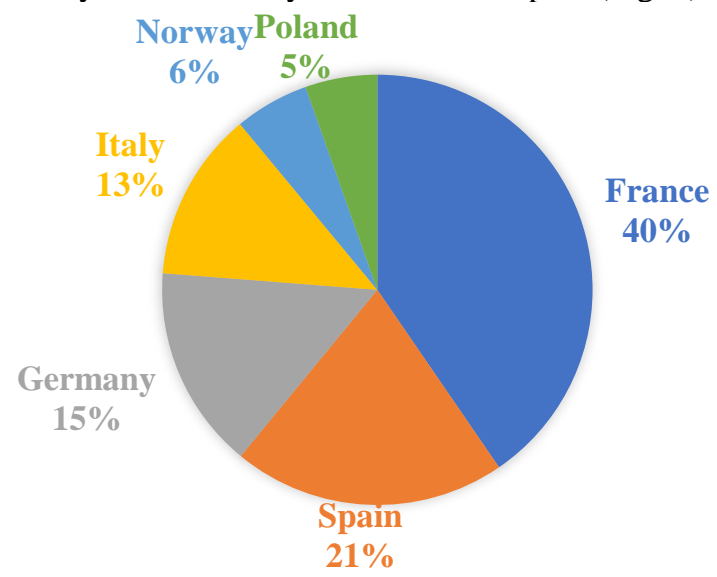

Fig.1. Number of biotechnology companies in Europe, 2019

There are both biotech companies and start-ups in the country, growing in number thanks to the synergies between industry, government, and the research sector in biotechnology (Figure 2). 


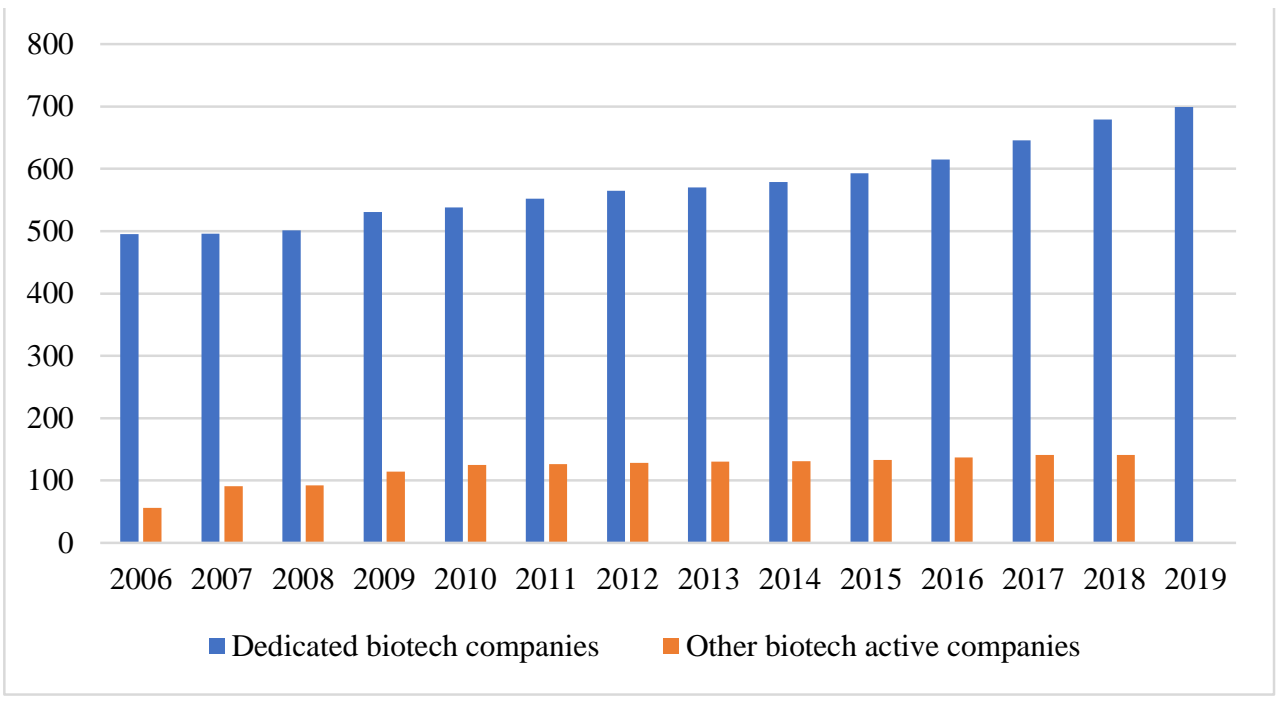

Fig 2. Biotechnology companies in Germany 2006-2019

R\&D spending showed a $21 \%$ boost over 2018. Most of the capital transferred to the development of new treatments and diagnostics. Compared to 2018 ( $€ 916.8$ million), the total increased by $7 \%$ to $€ 993.5$ million. In the second place, with an increase of $5.1 \%$ ( $€$ 14.3 million), are companies that are mainly engaged in bioinformatics. R\&D spending also increased slightly in industrial biotechnology $(+2.7 \%, € 55.9$ million $)$ [10].

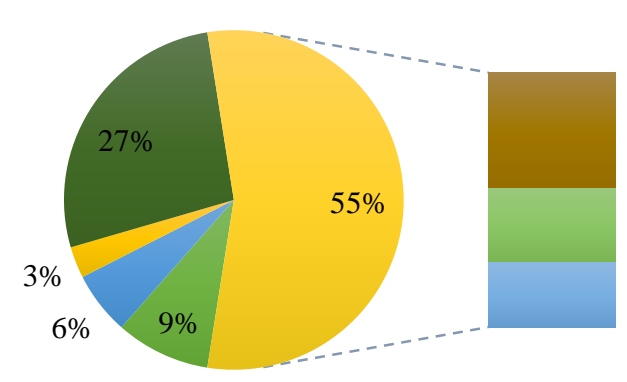

$\begin{aligned} & \text { Industrial biotechnology } \\ & \text { Bioinformatics } \\ 25 \% & \square \text { Agrobiotechnology } \\ & \square \text { Dedicated biotech services } \\ 16 \% & \square \text { Medical biotech } \\ 14 \% & \square \text { Drug development } \\ & \square \text { Diagnostics } \\ & \square \text { Services }\end{aligned}$

Fig 3 Share of German biotech companies in various sectors in 2020

Most listed companies (55\%) are active in medical biotechnology, 25\% of these companies are developing new drugs, for example, for the immunotherapy of cancer, autoimmune or neurological diseases (Figure 3 ). In addition, $16 \%$ are developing diagnostics, such as tests to recognize cancerous tumors or the rapid detection of pathogens and viruses. Another 14\% offer services for medical research. About one-tenth (9\%) of German biotech companies work in industrial biotechnology and develop biofuels, enzymes, food additives, or specialty chemicals. About $6 \%$ of companies work with big data and biotechnology that make up the bioinformatics sector [10].

The rapid evolution of the industry is also evidenced by its growing investment (Fig. 4). In 2018 , German biotech companies were able to raise 1.32 billion euros, the highest amount 
achieved in the last 14 years. Furthermore, although there was no initial public offering in 2018 , the companies could raise 2.5 times more funds than in 2017 , namely 898 million euros (2017: 352 million euros) from the capital market [10].

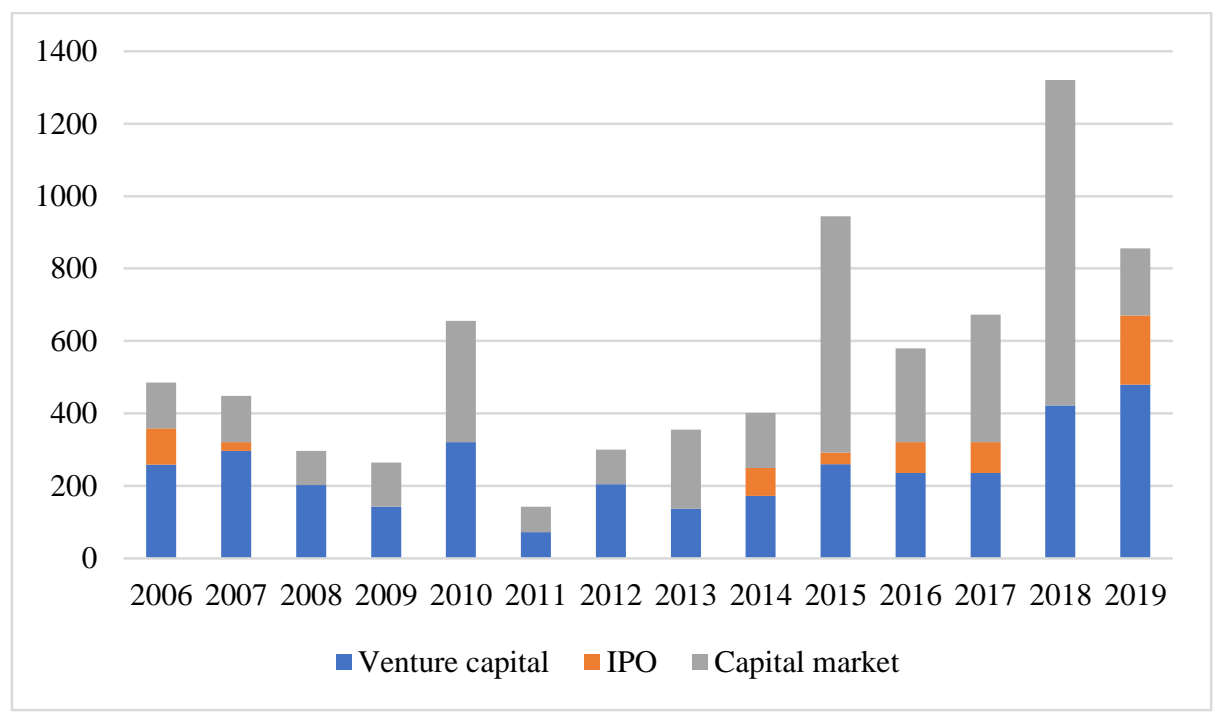

Fig. 4. Sources of funding for dedicated biotechnology companies in Germany 2006-2019.

Venture capital investment also increased significantly in 2018; companies received 422 million euros from venture capitalists, 79.6\% more than in the previous 2017. After the complete absence of IPOs in 2018, there were again two IPOs for a total of $€ 191$ million. As a result, the total number of venture capital rounds increased significantly again $(+24 \%)$ and reached a new high of $€ 479$ million in 2019. Venture capital and IPOs accounted for $78 \%$ of total funding, reaching the second highest ever in 2019 [11].

However, a large proportion of venture capital-funded by German startups goes to areas that can bring products to market much faster and with significantly lower costs and risks: mobile technology (1.6 billion euros), financial technology (2nd place), software and analytics ( $€ 1.2$ billion), and e-commerce ( $€ 0.7$ billion) (Figure 5).

Mobile technologies

$$
\begin{array}{r}
\text { Fintech } \\
\text { IT }
\end{array}
$$

Ecommerce

Healthcare

Other

Marketing technologies

Real estate technologies

Software development

Agrotechnology

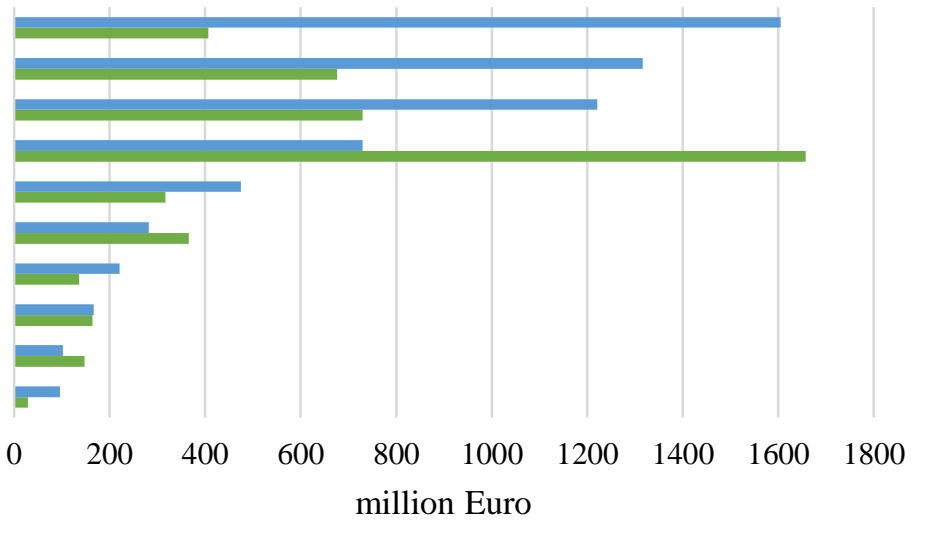

घ2019 2018

Fig.5 Venture funding of German startups by industry 2018-2019 
It is worth noting that investment in healthcare increased in 2019. Digital health received the most funds (38\% of total assets in the category), as well as for biotechnology (20\%) and medical technologies (19\%) (Figure 6).

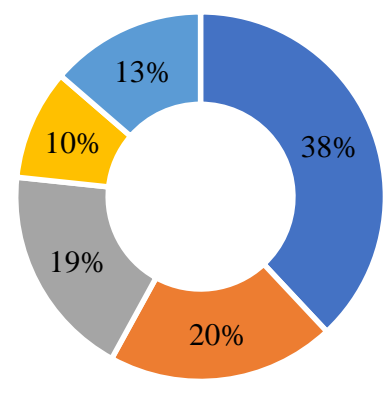

- Digital healthcare

- Biotech

- Medtech

- Bioscience

- Other

Fig. 6. The volume of venture capital investments in the healthcare sector in 2019

Compared to the total volume of venture capital investments in German startups, the share of biotech startups is relatively modest ( 0.095 billion euros; $1.5 \%$ of the total). This equates to just over $€ 90$ million for biotech startups across Germany. As a result, the industry's role in the region is not getting the "boost" it deserves to overgrow on the global stage.

One of the main problems of venture financing in the German biotechnology industry is the concentration of funds in a few large companies. As a result, investments in BioNTech are noticeably different in scale from other companies and startups (Figure 7). The current $\$ 270$ million ( $€ 228.8$ million) round at BioNTech is a record for private funding in Germany and accounts for almost $60 \%$ of total industry funding. Following this highly positive development, the level of financing for the rest of the companies in the industry fell to 157 million euros in terms of risk capital ( $22 \%$ compared to the previous year).

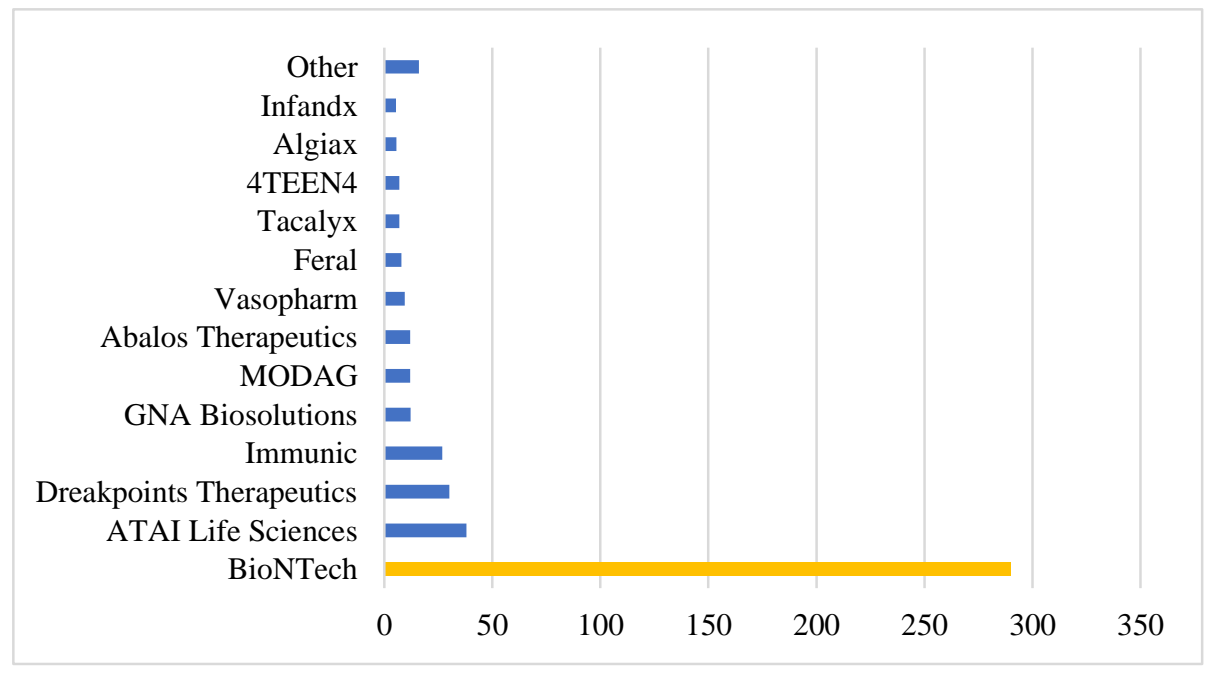

Fig 7. Venture financing of German biotech companies in million euros, 2019Источник: Source: compiled by the authors, data collected from [11-12] 
The size of these deals reflects several factors, including the maturity of the German venture capital ecosystem, investor confidence in proven companies with COVID-19 resilient business models, and Germany's thriving science ecosystem.

Numerous incubators provide startups with financial support, office or laboratory space, and business advice. Some also offer proximity to venture capital or networking opportunities with institutions, foundations, and industry representatives. In the mid-1990s, Germany created the BioRegio program to develop the biotech industry. The government has issued cash prizes to various regions across the country to help them build biotech companies and stimulate international investment [13].

More than 400 higher education institutions and about 1000 public research organizations are located on the country's territory, including the Max Planck, Helmholtz, Leibniz Society, and the Fraunhofer Association. In addition, Germany is world-famous as a Central European center of sciences.

Also, the country has a system of grants for the development of priority sectors. An example is the Invest grant for venture capital in the biotechnology field, which increases the capitalization of young innovative companies by subsidizing investments from private investors in startups. In addition, Kreditanstalt für Wiederaufbau (KfW) established a new subsidiary with KfW Capital in 2018. The aim of a joint initiative of the Federal Ministry of Economic Affairs and Energy, the Federal Ministry of Finance, and KfW is to strengthen venture capital in Germany and Europe and provide access to capital for young, innovative, fast-growing technology companies in Germany. And since January 1, 2016, the Federal Ministry of Economics has been implementing a health export initiative that helps make medical biotechnology products successful worldwide [14].

Public investment in the industry is widely used in Germany, which creates the preconditions for forming a favorable innovation environment. But, of course, not all biotech startups and companies can count on a federal grant or fund assistance since the resources provided are limited.

\subsection{Econometric Forecast of the German Biotechnology Market}

The value of the biotechnological production in million euros in Germany for 2008-2028, was chosen as the object of study and forecasting (represented in the model by the VALUE indicator).

The authors also selected several influencing factors that are considered in the constructed linear model:

- EMPLOYEE - number of personnel engaged in biotechnological research and experimental development (people)

- COSTS - R\&D expenditures of biotech companies (million euros)

- INVESTMENTS - investments in biotechnology companies (million euros)

To determine the level of influence of the selected factors on the volume of production of biotechnological research and experimental development, a linear model was built:

$$
V A L U E=\beta 1+\beta 2 \text { EMPLOYEE }+\beta 3 \text { COSTS }+\beta 4 \text { INVESTMENTS }
$$

The estimated equation is as follows:

$$
\text { VALUE }=-435+0.066 \text { EMPLOYEE + 0.67 COSTS + 0.4 INVESTMENTS }
$$

The coefficient of determination in the obtained equation is $\mathrm{R}^{\wedge} 2=0.867$, which allows us to conclude that changes in the level of biotech production and experimental development in Germany by $86.7 \%$ are explained by a change in the factors considered in the model and by $13.3 \%$ - by a change in other factors not included into the model. 
The obtained coefficients allow us to conclude that research and development costs have the most significant impact on the production volume of biotechnological companies.

To assess the quality of the resulting model and the possibility of predicting indicators based on it, a comparison was made between the actual and estimated values of the production volume of biotechnology companies for 2008-2019 (Table 1).

Table 1. Estimated values of the of the production volume of biotechnology companies for 20082019

\begin{tabular}{|c|c|c|c|c|c|c|c|}
\hline TEAR & VALUE & VALUE^ & Variance & $|\mathbf{E}|$ & $\mid \mathbf{E} / \mathbf{Q}$ & $\mathbf{E 2}$ & $\begin{array}{c}(\mathbf{Q}-\mathbf{F}) / \mathbf{Q}= \\
\mathbf{E} / \mathbf{Q}\end{array}$ \\
\hline 2008 & 1065.2 & 1136.4 & -71.2 & 71.2 & 0.1 & 5064.3 & -0.1 \\
\hline 2009 & 1219.1 & 1305.2 & -86.1 & 86.1 & 0.1 & 7419.4 & -0.1 \\
\hline 2010 & 1178.7 & 1403.7 & -225.0 & 225.0 & 0.2 & 50627.4 & -0.2 \\
\hline 2011 & 1021.2 & 1031.1 & -9.9 & 9.9 & 0.0 & 97.7 & 0.0 \\
\hline 2012 & 996.1 & 1008.9 & -12.8 & 12.8 & 0.0 & 163.3 & 0.0 \\
\hline 2013 & 1088.5 & 1004.8 & 83.7 & 83.7 & 0.1 & 6999.2 & 0.1 \\
\hline 2014 & 1228.2 & 1183.2 & 45.0 & 45.0 & 0.0 & 2021.0 & 0.0 \\
\hline 2015 & 1302.5 & 1282.7 & 19.8 & 19.8 & 0.0 & 391.4 & 0.0 \\
\hline 2016 & 1554.3 & 1474.1 & 80.2 & 80.2 & 0.1 & 6436.7 & 0.1 \\
\hline 2017 & 1814.6 & 1558.4 & 256.2 & 256.2 & 0.1 & 65624.6 & 0.1 \\
\hline 2018 & 1782.4 & 1853.2 & -70.8 & 70.8 & 0.0 & 5007.2 & 0.0 \\
\hline 2019 & 1839.8 & 1848.9 & -9.1 & 9.1 & 0.0 & 82.3 & 0.0 \\
\hline
\end{tabular}

Comparison using a line graph of actual values for 2008-2019. and obtained with the help of the model show coincidences (Figure 8), which once again proves the fact that the forecast error for several years ahead will be low. 


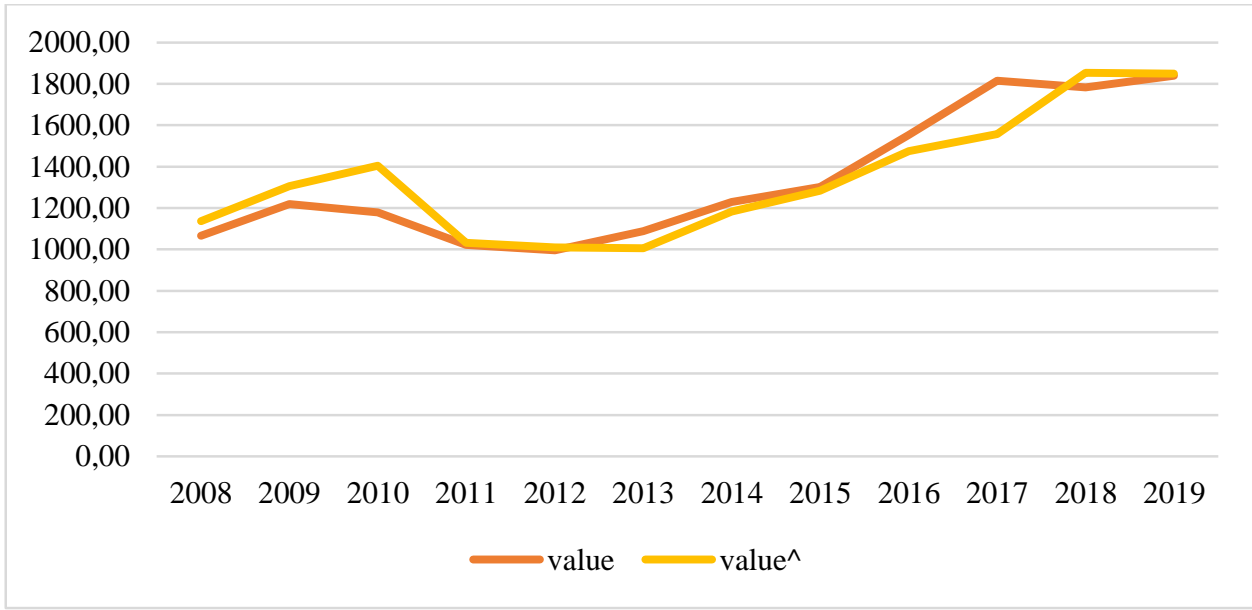

Fig. 8. Comparison of actual and model-derived biotechnology production in Germany 2008-2019

As a result, according to the obtained model, the values of the production volume of German biotechnological companies for 2020-2028 were predicted. (Figure 9)

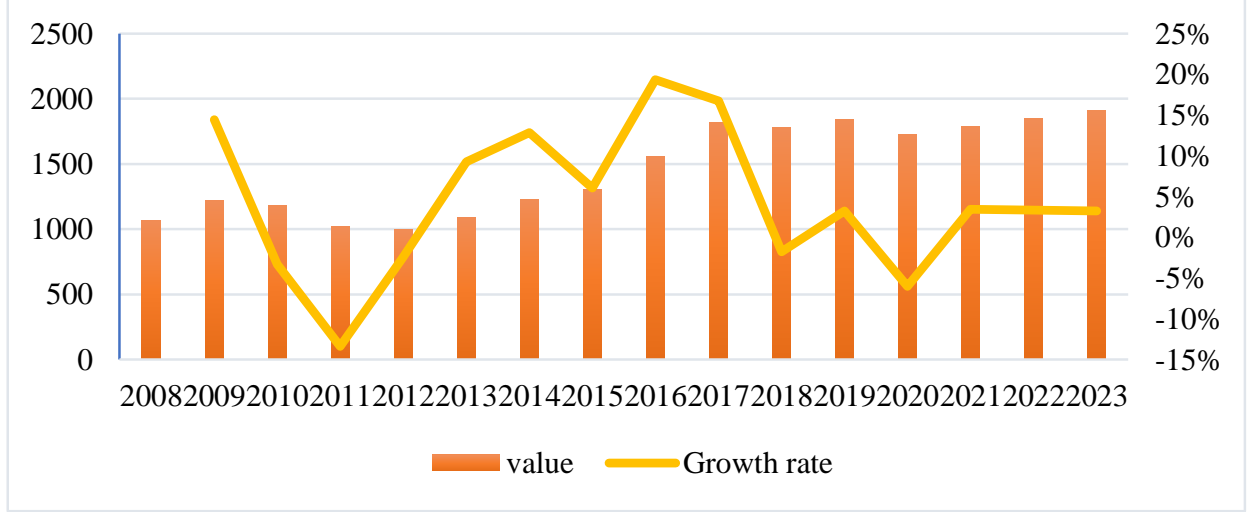

Fig.9. Production volume of German biotechnology companies in Germany 2008-2023

Since 2017, there has been a decrease in the growth rate of the indicator. A sharp reduction by $13.4 \%$ in $2011,6 \%$ in 2015 , and $1.8 \%$ in 2018 with high growth rates in other years led to the fact that the average value of the CAGR growth, which for $2008-2019$ amounted to $3.7 \%$, in the forecast period decreased to $3.3 \%$, respectively. Still, the production volume of biotech companies is expected to increase from 2020-2023. and by 2023, based on this model, the indicator will reach the value of 1907.79 million euros $(+20 \%$ by 2019$)$.

\section{Discussion}

Just over a year ago, the COVID-19 pandemic swept across the globe, having an incredible impact on society, economy, culture, and politics. With fatal consequences for health systems, the rapid spread of the pandemic has taken all sectors by surprise. As a result, the measures to contain the pandemic had to be developed in a time-constrained environment.

Biotechnology played a crucial role in overcoming these challenges, as it provided the basis for modern sequencing techniques that quickly led to the genetic mapping of the virus; development of a diagnostic PCR test; identification of antigens for the development of 
antibody tests; the development of mRNA vaccines, which became the first class of vaccines to receive EU and US approval in record time.

The enormous spread of SARS-CoV-2 and the associated need to deal with the problem as quickly as possible led to German bioregions spontaneously taking responsibility, initiating, and organizing many measures. Almost every region has created an online platform where information related to COVID-19 was made available to companies, citizens, and politicians. Many of these platforms served as a "marketplace" for exchanging requests and proposals for co-manufacturing and provision of test systems, protective clothing, or medical equipment, for example, for ventilating patients or cleaning indoor air from viruses [15].

However, even more, important than the Internet platforms was the personal commitment of regional managers and their teams. In Berlin, for example, HealthCapital launched the SARS-CoV-2 Diagnostics Topic Group, in which academics, hospitals, and industry met weekly to develop new concepts to expand urgently needed testing capabilities. In addition, BioRegio Regensburg has created a "Crown Task Force" at Biopark to advise and support companies on financial support, labor relations, events, and health regulations. In many regions, such as Stuttgart, Münster, or Saxony, companies have been motivated to re-equip their laboratory facilities for coronavirus testing, make them available, or even suspend their strategic business model [13].

The crisis that has brought with it COVID-19 has given rise to new confidences. However, the German biotech sector has been in the spotlight, thanks in part to the BioNTech vaccine and the CureVac vaccine candidate. Comparison of all German listed companies in 2019 and 2020 shows a significant increase in market capitalization of about $111 \%$. BioNTech alone accounts for $33 \%$ of the total market capitalization of German biotech companies, up 134\% from 2019, while CureVac, which went public in August 2020, accounts for about $24 \%$. The significant increase in market capitalization shows that the German biotech sector has received a significant increase in confidence in the capital market, thanks partly to the COVID 19 pandemic [12].

Although the two companies mentioned are only two representatives of the biotechnology market, their success is reflected in the industry. It became clear that biotechnology can provide answers to the main questions facing humanity not only to the fight against disease but also to other important issues such as climate protection, energy production, and food supply for the world's population.

Following the massive success of BioNTech's coronavirus vaccine, media, public, and policy interest in the local biotech industry and its offerings has skyrocketed. The BioNTech example illustrates what is necessary for success and what is often lacking in Germany.

Funding is, of course, an essential factor. BioNTech, a project of the University of Mainz, received massive early-stage support with $€ 150$ million in seed funding from the private sector. In addition, the company was initially supported for many years by the GO-Bio funding program of the German Federal Ministry for Education and Research. Cooperation with other companies has made it possible to implement significant development and commercialization programs. In 2018 and 2019, there were extensive series A and B funding, followed by a successful IPO on the Nasdaq. In 2020, the company began developing the Corona vaccine. Outstanding scientists, good start-up funding, sufficient start-up capital, and an IPO have made BioNTech a success. Unfortunately, there are too few such stories in Germany [16].

Why is this happening in a country where science education and research are among the best and highly respected worldwide? Moreover, why are there only a handful of large and successful biotech companies in one of Europe's most funded markets?

First, the country needs to rethink its financing policy for the industry. Funds attracted to German biotech start-ups rarely reach such volumes as in BioNTech, especially during the growth phase. While IPOs have reappeared in finance lately, they now almost always take 
place in the US. Unlike Germany, there is a well-functioning capital market ecosystem with many institutional investors investing in biotechnology and a much larger number of biotech analysts.

Secondly, it is necessary to change the attitude towards risk since it is an integral component. Yes, many of the potentially disruptive innovations can fail, but the overwhelming success of a few will lead to significant benefits. By comparison, in 2020 alone, the German government invested about 1 billion euros in accelerating the development and production of the Corona vaccine. At the same time, more than $\$ 12$ billion had already been spent in the United States on Operation Warp Speed to develop a vaccine.

Third, it is worth paying more attention to government programs and incentives for German biotech start-ups. For example, the GO-Bio program, which was created to help budding biotech start-ups and propelled BioNTech to success, has not been renewed since 2018. In addition, it is the only start-up finance program specifically tailored to the needs of our industry. Likewise, the KMU-Innovativ BioChance funding program was suspended in early 2019. This proven medical research funding program has yet to be resumed or replaced correctly. Another barrier is the amendment to the Law on Foreign Trade and Payments, making it difficult for investors from non-EU countries to invest in European companies.

In any case, just improving the image of the industry in the public's eyes against the background of the fight against global problems is not enough. The more important factors for achieving real change are the appetite for risk-taking and the public sector's willingness to pay sufficient attention to the industry to improve the investment environment. Moreover, if these changes do happen soon, the German biotech industry has a chance to enhance its presence in the biotechnology market and noticeably increase the growth rates in the industry, which, even before the pandemic, tended to grow.

\section{Conclusion}

The biotechnology industry continues to expand worldwide as it finds application in almost all spheres of human activity. These are medical advances: new drugs and procedures necessary for the treatment and prevention of diseases, the production of advanced prostheses and neural implants; environmental awareness: ways to preserve and maintain it, using alternative clean energy; agricultural development. In computer science, the development of the biotechnology industry is driving an increase in the amount of bio data collected, which creates a need for new computer programs and analytical methods.

Traditionally, the United States is considered the world leader in biotechnology innovation. In 2019, the country occupied about half of the total market volume and was the leader among registered patents in biotechnology. However, as globalization becomes more visible and technology spreads worldwide, other countries are gradually coming to the fore in the biotech arena. The Asia-Pacific region is rapidly increasing its position, currently occupying a quarter of the biotechnology market. The country actively stimulates innovation activity, invests in $\mathrm{R} \& \mathrm{D}$, and pays great attention to state policy in this area. European countries round out the top three with a presence of $18 \%$ of the market in 2019. At the same time, only a few countries stand out, mainly Germany, Great Britain, and France.

Germany is one of the biotechnology leaders, and the climate for the development of commercial biotechnology is only getting better, which positively affects the number of new enterprises specializing in this field. The number of companies from 2015 to 2019 increased by $20.7 \%$. In terms of funding for the biotechnology industry, Germany remains the leader in Europe. Most of the funds raised are venture capital and IPOs (78\% of the total budget in the industry in 2019). The most popular application of biotechnology in Germany is medicine (about $70 \%$ of all enterprises) which is especially important because of the recent changes caused by Covid-19. 
Even with such positive indicators, the country has been at about the same level for several years now, not significantly increasing its position in the global biotechnological arena. The authors determined several reasons for such situation: difficulty for the German biotech startup to obtain funds at the initial stage, since investments are mainly made in large and more stable companies; many government programs to support new businesses in the industry have ceased operations; a conservative attitude towards risk does not fully benefit from the industry.

The forecast results reflect the fact that German biotechnology is constantly evolving, even without taking into account the impact of the pandemic. As a result, the industry shows stable growth in the forecast period 2020-2023, with a CAGR of 3.3\%. Furthermore, financing policy revision may increase this indicator and develop measures of state support for small biotechnological enterprises. Thus, the industry's growth leads to an improvement in the innovative potential of the country, growth of the national economy as a whole, and strengthening the position in the international arena.

The article was prepared with the financial support of the RUDN University Economic Faculty, project № 060326-0-000.

\section{References}

1. M. Vitolo, Pharmaceutical Biotechnology (CRC Press, 2021)

2. E. DaSilva, Electronic Journal of Biotechnology 7, 3458 (2005)

3. Perju-Mitran, Biotech Market, 229 (2019)

4. H. Ruhrmann, M. Fritsch, L. Leydesdorff, Regional Studies, 1, 12 (2021)

5. S. Friedrichs, S. OECD Science, Technology and Industry Working Papers, 6, (2018)

6. M. S. Reshetnikova. Modern Global Economic System: Evolutional Development vs. Revolutionary Leap, (Springer International Publishing, 2021)

7. OECD, Key Biotechnology Indicators, http://oe.cd/kbi, October 2020

8. M. McCoy, C\&EN Global Enterprise 98, (2020)

9. German Pharmaceutical Industry Association. Pharma-Data (2019), https://www.bpi.de

10. The German statistical office, https://www.biodeutschland.org/en/

11. Bellucci, G. Gucciardi, D. Nepelski, D. Venture Capital in Europe. Evidence-based insights about Venture Capitalists and venture capital-backed firms. (2021)

12. Widener, C\&EN Global Enterprise ,99, (2021)

13. M. Frincu, BIOREGIO - Supporting Circularity in the Bio-Based Economy57, (2020)

14. P. Volberding, Leveraging financial markets for development: how KfW revolutionized development finance (Piter Fol'berding, 2021)

15. M. Schulz, Germany and Covid-19, (2021)

16. E. Mahase, BMJ 371, (2020) 